\title{
Cultural diversity and new media - their interaction as an element of European integration: Elaborating a European research network
}

\author{
Gerhard Banse, Karlsruhe and Andreas Metzner-Szigeth, Münster
}

\section{Introduction}

The paper first summarises the background of the genesis and the subsequent development of the European research network "cultural diversity and new media" (CulTMEDIA). Then it gives an introduction into the leading questions and basic approaches of its research programme. The three main strategic objectives addressed by CuLTMEDIA are 1.) to update the scientific debate concerning the relationship of culture and media, 2.) to research the interactions between cultural diversity and new media, and 3.) to discuss their role as an element of European integration. They are subsequently tackled in the following chapters which outline how CULTMEDIA's research activities could be - and, meanwhile, after some years of network activities, have been elaborated on three levels, the "abstractconceptional", the "discursive-comparative", and the "synthetic-conciliar" level of research. Chapter 4 deals above all with the notions of culture, technology and communication in order to establish an analytical framework for the assessment of the civilizational importance of the emerging ubiquitous system of computer-mediated communication. Chapter 5 concentrates on the identification of the four central fields of the network's research: "privacy and the public sphere" (for the socio-political dimension of the subject), "identity and the community" (for its social-cultural dimension), "knowledge and the economy" (for its socio-economic dimension), and (more as a cross-sectional topic) "security/insecurity and trust". Chapter 6 considers the theoretical approach of CULTMEDIA while discussing the interdependencies and exchange relations of cultural diversity and new media regarding their importance, consequences and meaning for the process of European integration. Finally, the paper gives an outlook describing ongoing pursuits and wishes for the near future that reflect the present phase of the network's consolidation.

\section{Preliminary remark}

This contribution describes the foundation process and the conceptual elaboration of a European research network which is dedicated to the socio-cultural consequences and potentials of the new media. It originated from a loose association of lasting bi- and multilateral cooperative working relations and was founded in 2002, at first under the title "new media and culture - the example of the internet" (NEMET). Meanwhile (since 2003) its name has been "cultural diversity and new media - their interaction as an element of European integration” (CULTMEDIA). The members of the network represent a variety of disciplinary perspectives. They come from cultural sciences and humanities, social sciences and psychology, as well as computer sciences and communication/media studies.

Background of the foundation of CuLTMEDIA were the results of a study that was carried out by the Office for Technology Assessment (Büro für Technikfolgenabschätzung; TAB) of the German Federal Parliament (Deutscher Bundestag) during the years 2000 and 2001 (cf. Paschen et al. 2002). This study was stimulated by the Committee for Culture and Media of the German Federal Parliament. Its objective was to analyze recent and future effects of the development of new media on the concept of culture, the politics of culture, the economy of culture and the actuation of culture itself. The focus of the study was laid - apart from 
considerations about changing patterns of cultural understandings and cultural concepts - on the topics "new media and media markets" as well as on "new forms in the production, mediation and reception" in selected cultural areas (literature, music, cinema).

The current changes in the field of the new media and the media markets whose effects were examined exemplarily for traditional cultural fields were pointed out clearly during the study. However, it was also shown that the findings gained in the national frame must be broadened by their European dimensions. In this regard, CuLTMEDIA now examines cultural changes in different national contexts while following two priorities: firstly, it refers to the internet as the representative of the new media; secondly, it refers to such cultural practices which change in the life-world and systemic contexts of the everyday use of this sociotechnical medium. General interdisciplinary analyses are thereby combined with multinational comparisons (cf. also Banse et al. 2000).

The task of the network is some deeper analysis of the changes of cultural practices (for instance patterns of use, use motivations and use situations) which are connected with the application of the internet. Within the past years, research about network-based communication has developed with a similar pace as the internet itself (cf. e.g., Grunwald et al. 2006). The relevance of this relatively new research field results from the great importance that is attached to the internet by several huge social trends (as for example the globalisation). The internet leads to a new quality of the mediation of humans to humans and humans to nature thanks to its universal character, global nature, high speed and great availability. It takes essentially part in the reconstruction of the world, a fact that is expressed for instance in the emerging tension-relation of reality and virtuality. The alterations resulting from these trends are often assessed as a major cultural change with effects on all fields of life in the modern societies.

Since 2004, the network has been editing a book series of its own, "e-Culture/Network Cultural Diversity and New Media”, published by the trafo-Wissenschaftsverlag Dr. Wolfgang Weist, Berlin. So far, 13 volumes have appeared and two more are being prepared. ${ }^{1}$

In order to consolidate itself as a network of cooperative working relations and to strengthen its financial basis, CULTMEDIA is engaged in elaborating proposals for the European Commission, ("Network of Excellence"), the European Science Foundation ("Exploratory Workshop"), the COST-programme (as well as several other national and transnational funding agencies).

\section{Overview}

In chapter " 1 . Introduction", the subject matter of CULTMEDIA is presented, reasons for its research project are provided and further explanations are given. This is carried out in three stages. The first stage (Chapter 3.1) outlines the historical background and provides a general introduction into the relationship of media and culture development. The second stage (Chapter 3.2) explains the research subject of CultMEDiA in several steps, i.e., the interrelations of cultural diversity and new media and their role in the process of European integration. The third stage (Chapter 3.3) offers a structural overview of the research levels within the network, which also serves as a preliminary outline for further explanations.

\subsection{Media \& culture - historical background}

There has always been a close relationship between the cultural development of Europe's peoples and the utilisation of communication media. Such connections also apply with regard

\footnotetext{
${ }^{1}$ Cf. http://www.trafoberlin.de/ $\rightarrow$ Wissenschaftsverlag $\rightarrow$ Reihen $\rightarrow$ e-Culture.
} 
to the development and utilisation of digital media in connection with that of computermediated communication and the transformation of modern societies (cf. Banse, Grunwald, and Rader 2002).

The possibilities for societies to elaborate, distribute, store, use and revise information and knowledge constitute an important dynamic factor of socio-cultural change. The beginning of script culture, the invention of book printing or the "modern" media such as press, radio and above all TV have made a considerable contribution to cultural and social changes producing serious consequences. According to the information and communicationtechnological development dynamics, it also makes sense to consider the cultural conditions and implications of the information and communication possibilities represented by the internet, which for the purpose of a better terminology are summarised as "new media". However, it must be considered here that the structural change of cultural practices to be investigated is not merely induced by technology, but is also connected with interrelated social developmental processes; increase in globalisation, individualisation, reflexive modernisation, complexity and contingency as well as a change in values are keywords that occur in this context.

CULTMEDIA now intends to make its research subject cultural changes in the wake of the so-called "new media" with regard to the following two priorities: first, it refers to the internet as the representative of the new media, and second, it refers to those cultural practices that are changing in the lifeworld ${ }^{2}$-related and systemic connections of the everyday use of this socio-technical medium. In addition to general interdisciplinary analyses, the main emphasis is placed on multinational comparisons.

\subsection{The network's subject of research}

Against this background, CultMediA investigates these changes in relation to sociality (formation of individual and collective identities, forms of community building) and culturality (cultural practices and goods as content patterns of social life), which result in connection with the development and utilisation of the internet (as a medium for technical information and communication). Thus the network investigates changes and processes that transform the present European society/societies and that constitute a major part of its transition to a "knowledge-based society".

These changes take place in the European Union in an environment of extreme cultural diversity and are thus influenced in their form and process (speed, direction, pattern). Conversely, they simultaneously influence this environment and change the dynamics within which diversified national cultures within the EU develop further in mutual solidarity.

The interactions between "cultural diversity" and "new media" develop in a complex matrix, the salient points of which are set through the terms "culture", "society", "media" and "technology". As far as "society" is concerned, the conditions of influence of social subsystems, the way organisations work and the interaction opportunities of individuals all change in connection with the transformation of their cultural foundations through the extensive use of new media. It is not the sum of the changes in all fields of interaction and life that is decisive but primarily also the changing relationship of penetration and delimitation between "life-world" and "systemic" references of communication and action.

In order to be able to understand the form and importance of cultural transformations which take place in connection with the development of new media, two subjects shall be reflected: on the one hand, the subject of "reality and virtuality" and, on the other hand, that of "space and time". Both subjects are to be considered systematically during the

2 Cf. McIntosh 1997 for an assessment of Jürgen Habermas's distinction between system and life-world (cf. Habermas 1981a, 1981b, cf. also Habermas 1989). 
investigation of the three research fields (determined later) and the cross-sectional topic. Here it is decisive that the cultural transformations are not simply a series of extended possibilities of communication and symbol processing or their broader use, but that the new media are essentially characterised by the fact that they make the relationships of virtuality and reality and space and time available and usable to an extent which has been unknown so far and that they "reconstruct" them in a complex way. Instead of supporting one-dimensional theses, such as a "softer" reference to reality through virtuality or a "shrinking" of space through electronic communication, it shall be shown which design potential new media have for creating new relationships, e.g., through the possible access to an enormous reservoir of information sources and stock of knowledge at any time and all over the world.

\subsubsection{Homogenisation versus diversification}

As far as the interactions of "cultural diversity" and "new media" are concerned with reference to their consequences for the "cultural diversity", it must be assumed that neither the hypothesis of continuous cultural homogenisation nor the hypothesis of continuous cultural diversification can be proved. The concern is rather with an area of tension between the poles of which - homogenisation versus diversification - a terrain of complex overlapping and diverse design options is created. What shape this overlapping takes depends on how it is designed socially, the contextual conditions (language and cultural differences between the European nations) and the forces that act upon it. The form of the interactions between "cultural diversity" and "new media" is not only determined by the characteristics of the "new media", but also by the way in which optional connections become concrete under the influence of protagonist coalitions (network operators, content providers, user groups, media and cultural policy) and macrosocietal processes such as (commercial) globalisation, individualisation or reflexive modernisation.

\subsubsection{Fields of research}

In order to incorporate the interactions between "cultural diversity" and "new media" in their function as an element of European integration, they are investigated by comparing European nations.

In order to capture the scope and complexity of possible interactions, the implication of cultural transformations is to be explored in the field of social, political and economical dimensions. The three areas of research delimited by CULTMEDIA not only analyse these three dimensions, but also place an emphasis on three research topics that are an important prerequisite for the gaining of an individual understanding of all the current processes of change that are of utmost importance for the further development in Europe.

- Research area 1, "privacy and the public sphere", analyses the socio-political dimension of the topic "cultural diversity and new media" with the help of the following question: What is going to change in the relationship of privacy and the public sphere under the influence of new media?

- Research area 2, "identity and the community", analyses the socio-cultural dimension of the topic "cultural diversity and new media" with the help of the following question: What is going to change in the relationship between identity and community under the influence of new media?

- Research area 3, "knowledge and the economy", analyses the socio-economical dimension of the topic "cultural diversity and new media" with the help of the following question: What is going to change in the relationship between knowledge and economy under the influence of new media? 
- In addition, there is the cross-sectional topic "security/insecurity and trust". The research problem of this topic, the changed balance of these two fundamental parameters for the constituency of modern societies, unfolds in the intersectional plane of the three areas of research. It is investigated by means of the following question: What changes, problems and approaches to solving the problems result with regard to the relationship of security/insecurity and trust in the three areas of research "privacy and the public sphere" (e.g., digital signatures - cf. Langenbach and Ulrich 2002), "identity and the community" (e.g., theft of identities) as well as "knowledge and the economy" (e.g., unauthorised changes)?

\subsubsection{European integration}

By means of comparative investigation of the interactions of cultural diversity and new media in the three areas of research as well as for the cross-sectional topic, not only the pattern of the interactions in question is to be identified, but it should also be investigated to what extent this pattern varies between European nations. Instead of "only" leading a general discussion on cultural diversity as an element of European integration, for instance the question of whether it is to be understood as a strength or a weakness, the question regarding the connection of cultural diversity and new media is investigated within the context of four concrete complexes which are of vital importance for the development of the present European society/societies and the progress of the integration processes within the EU.

In order to complete this investigation and to contribute to the practical implementation of its results, the CulTMEDiA finally considers what consequences can be derived for wellfounded support of the media and cultural policies of the EU and of its member states. The problem here is not only the coherence of its guidelines, but also their approaches and instruments as well as the question of whether there is a special need for action within the framework of the current European expansion, and what measures can be taken to meet this.

\subsection{The network's three levels of research}

The research work of CULTMEDIA is to be carried out on three levels, which are based on each another but do not necessarily have to be executed in succession, in so far as their interrelation has to be considered. They will be briefly outlined here and described in more detail in Chapters 4, 5 and 6 in connection with the determination of the research tasks related to them, which will be intensively worked on during the later periods of research carried out by the members of CULTMEDIA.

- On the first level, which will be described in more detail in Chapter 4 of this paper, the task is to continue the abstract-conceptional work, to look at it in greater depth and to review it in a reflective manner. This will be achieved by means of state-of-the-art research regarding the interactions of culture and media, which will be presented in the following part together with open questions, and difficulties regarding the posing of the problem. In this context, the fundamental concepts of culture, technology, media and communication ${ }^{3}$

\footnotetext{
3 Further abstract-conceptional formulations, which are directly connected to the discursive-comparative research level, i.e., regarding the connections of "community" and "identity", "public sphere” and "privacy”, "knowledge and economies" as well as "security/insecurity and trust", will be elaborated later. The same applies to the abstract-conceptional formulations for "cultural identity”, "European identity” and "European integration”, which are directly connected to the synthetic-conciliar level of research.
} 
will mainly be dealt with. In this chapter they will be explained in two paragraphs that connect the correlations of culture and society on the one hand (cf. 4.1.), and those of technology and media (cf. 4.2.) on the other.

- On the second level, which will be introduced in Chapter 5, the main problem concerns discursiv-comparative research devoted to the current interactions of cultural diversity and new media, especially in the three areas of research introduced above as well as regarding the cross-sectional topic mentioned. First, the area of tension between homogenisation versus diversification will be examined in the context of a discussion of the general connection of media development and cultural change (cf. 5.1.). Second, the interactions will be investigated in connection with the three areas of tension and for the crosssectional topic with the objective being a comparative elaboration of their patterns (cf. 5.2.).

- On the third level, which is presented in Chapter 6, the task is to work in a synthetic-operational/conciliar manner, which means developing conclusions, elaborating recommendations and identifying steps for their implementation. Thereby, the role of the interactions (of cultural diversity and new media) as an "element of European integration" is in the focus of attention. In this context, the importance of "cultural identity" (national identity - European identity) for the process of European integration comes first, considered in terms of the connections of their political and economical contextual conditions (cf. 6.1.). Second, conclusions will be drawn from the comparison of the above-mentioned interactional patterns between cultural diversity and new media in the three areas of research and for the cross-sectional topic (cf. 6.2.). Third, against this background recommendations will be developed for the further shaping of European media and cultural policies (cf. 6.3.).

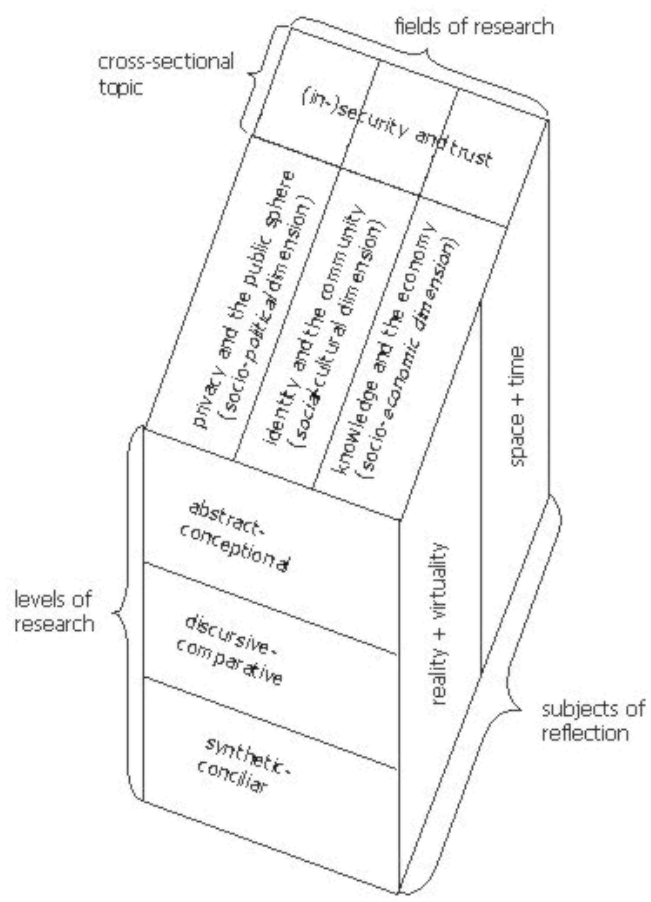

Figure 1: Overview of the scientific design of CultMediA: Research levels, research fields and subjects of reflection (source: by the authors) 


\section{Abstract-conceptional research-level: Relationship of culture and media}

The abstract-conceptional level of CuLTMEDiA's research work is the central focus for explanation in this chapter. The interactions between cultural diversity and new media unfold in a complex matrix, the salient points of which are marked by the concepts "culture", "society", "technology" and "media". In this chapter they will be discussed in two paragraphs that combine the connections between culture and society on the one hand (cf. 4.1.) and those between technology and media on the other (cf. 4.2.).

Concepts are not true or false, but rather more or less appropriate to the purpose for which they are used and constructed. CulTMEDIA's purpose is to work out the interactions between cultural diversity and new media and to comprehend what role they play for European integration. Thus CuLTMEDIA cannot be satisfied by identifying an individual, clear concept of culture, technology or media and using this as a basis. As a consequence, the task is not to identify individual concepts as "right" or the theoretically most "advanced". On the contrary, the first goal is to identify the variety of meanings encompassed by these words in science and society. Furthermore the complexity of the discourse should be taken into account. Only against this background can the multifarious interactions of cultural diversity and new media be accessed, consolidated and expanded, i.e., made workable for the research tasks to be dealt with.

CULTMEDiA does not pursue a single approach (which would also contradict its professed interdisciplinarity!), but is under an obligation to follow a variety of scientific perspectives. However, this does not suggest an arbitrary nature: the starting point is a common concept, even if it is "blurred at the edges", including certain conceptual preconceptions, the suitability of which for solving the problems under consideration is always open to revision. In the following section, conceptional-abstract points of departure will be dealt with, which are to be understood in the sense of presuppositions to guide knowledge and actions.

\subsection{Culture and society - a changing relationship}

As far as "society" is concerned, in connection with the transformation of its cultural foundations, the conditions of activity in societal subsystems, the way in which organisations work and the individuals' possibilities of interaction change through the extended use of the new media. However, it is not the sum of the changes in all fields of interaction and spheres of life that is decisive, but mainly the changing relationship of penetration and delimitation between "life-world" and "systemic" references of communication and action.

"Culture" is conventionally distinguished according to space and area of distribution (regional, national, international cultures), according to social acceptance and/or representativeness (advanced civilisation, subculture), according to specificity of social systems (industrial culture, sport culture), according to the representatives (court culture, cloister culture, youth culture) and according to the bonds with certain types of manifestation (music culture), where the time component is always intrinsic.

For the present it must be assumed that in sum these partial cultures do not fit together to a neat cultural whole, which would make it possible to deduce generally binding orientations. The fact that this cultural variety is reflected in a variety of concepts and understanding of culture corresponds to these results.

With regard to its importance and use, "culture" belongs to the scientifically most delicate and at the same time exhausted notions. In the past decades, the notion of culture has experienced a boom that goes far beyond academic debates. The latest development of the media has taken place against the background of this boom, and what is regarded as possible consequences of media development on the understanding of "culture" depends on the historically developed concept of culture that is used as a basis. 
In this context, first of all the most important types of notions of culture have to be distinguished. A commonly used differentiation is made between ethnographic or ethnological and those strongly normative notions of culture from the tradition of humanism (cf. King 1993: 2). Another possible differentiation is made between "culture" as a way of living in general (ethnological concept of culture), as art, as a humanely organised way of living (committed normative concept of culture of humanistic tradition) and as a symbolically negotiated sphere of values and norms in society (cf. Fuchs 1999: 220-221).

According to Siegfried J. Schmidt, the present boom of the notion of culture in science and politics is not simply a current fashion, but rather an "indication of a significant social development", a "development from the dominance of material factors to a dominance of knowledge", which, in turn, is considerably influenced by the development of information and communication technologies (cf. Schmidt 2000: 32-33).

\subsubsection{Culture - territoriality - globalisation}

A striking characteristic of new media is the fact that their spread changes the cultural importance of spatial closeness and distance. The widespread view is that the networked individual grows with their actions in the communication network beyond the borders of nationally constituted societies, and the possibilities of transnational cultural exchange and individualisation increase. This is promoted by the general tendencies of globalisation, which give a great deal of significance to the current change of concepts of culture.

Due to various stimuli, in the past years new approaches to investigating the relationship between "western" and other world regions have developed and so, too, has an increased interest in individual and collective acquisition processes of cultural contents distributed by mass media. The importance of these acquisition processes for the cultural change in the different world regions may lie in the alternative (detached from the traditional spatial context of experience) life plans which become available, in the "possible lives” which are conveyed by the media (cf. Appadurai 1996). The possibilities of computer-assisted communication of those who are spatially far apart and the increasing cultural importance of migrations will probably result in a further increase in the importance of ethnological topics - such as "virtual ethnicity" and "cultural hybridisation".

In the debate about traditional notions of culture, new concepts of culture are sometimes created that - although they are often not thoroughly outlined and only elaborated as first attempts - show some common characteristics: the individual is placed in the centre of the cultural-theoretical interest again, where, among other things, special relevance is attributed to post-traditional forms of community building and transnational links. There is a tendency of "liquefaction" and "de-territorialisation" of the notion of culture, and special emphasis is placed on aspects of the connection between cultural change and cultural globalisation. If this tendency is continued, a central topic of cultural-political debates could be the question of what role a future "transnational state" (cf. Beck 1997) could play regarding the global "cultural space of the internet".

Processes of individualisation as well as globalisation cause a relativisation of the cultural relevance of the social relationships that are characterised by spatial closeness. We are no longer dependent on the local community as a source of information, experience, entertainment, a feeling of security and the way in which we see ourselves to the same extent as before. According to widespread belief, the tendency of relativisation of cultural relevance of spatial nearness is closely connected with the latest development of the media, but also with migration and tourism. ${ }^{4}$

\footnotetext{
${ }^{4}$ However, the perception of this tendency should not tempt us to neglect local aspects. There are attempts to take this into account with concepts such as that of "glocalisation” (Robertson 1998).
} 
Thus polarisations such as "globalisation versus localisation", "homogenisation versus heterogenisation" or "universalism versus particularism" do not lead us anywhere. The fact that they still characterise the debates on the interactions between globalisation and media development is probably due to the novelty of the developments in question.

\subsubsection{Towards a modern notion of culture suitable for the project}

The answer to the question of what is to be understood by an up-to-date notion of culture therefore becomes a central starting point of CULTMEDIA. In order to back up CULTMEDIA's work on the discursive-comparative (second) research level, a notion of culture is needed which allows an understanding of cultural diversity in such a way that it is not only possible to pick out the interactions between cultural diversity and new media as a central topic, but also especially in the four areas of research chosen.

It is natural to choose a relatively broad notion of culture in this context, such as the one from the final declaration of the World Conference on Cultural Policy held in Mexico in 1982. ${ }^{5}$ However, its notion of culture is too general, not specific enough, and above all, cannot be operationalised. Only a sufficiently broad notion of culture opens up the possibility of observing how the media changes influence cultural structures, organisational forms and ways of communication and interaction ("communicative action”, truth, authenticity, etc.).

Despite this, the starting point of our further considerations is less extensional and more genetic: culture is formed within processes of cognitive, emotional and practical debate between interacting individuals regarding the conditions for their actions, which, on their part, not only include social, but also technical and ecological dimensions.

The following definition, which is to be understood in the sense of a first approach, could be appropriate for the concerns of the CuLTMEDIA project: according to this definition, culture is the result of the human being's coping with life and existence in an action-based and communication-based community, in other words, the "spatially-temporally restrictable totality of common material and non-material products, internalised values and interpretations of meanings as well as institutionalised forms of human life” (Klein 2000). Thus if culture is understood as "the totality of conscious and unconscious collective patterns of thinking, feeling and acting, which are socially acquired and handed down by people as members of a society and constitute a specific, characteristic of this society that can be delimited" (Hermeking 2001: 18), then this follows both the summarising and "classical" considerations of Alfred L. Kroeber and Clyde Kluckholm, who explicitly include „the achievements expressed in the material goods produced" in culture (cf. Kroeber and Kluckholm 1952: 181), and Arnold Gehlen's starting point for whom culture is the "epitome of materials/equipment, of expert technology and thinking techniques” (Gehlen 1958: 86).

Determining parts of this understanding of culture are mainly:

- non-material as well as material (concretised, "reified”) areas;

- handed-down, long-lasting productions;

- both spatially ("community") and temporally limited or delimited (also: distinguished) material and non-material "patterns";

- the aspects of being both, a product resulting from actions and an element that takes part in the formation of further actions.

\footnotetext{
5 There it is stressed that "the Conference agrees: that in its widest sense, culture may now be said to be the whole complex of distinctive spiritual, material, intellectual and emotional features that characterize a society or social group. It includes not only the arts and letters, but also modes of life, the fundamental rights of the human being, value systems, traditions and beliefs” (UNESCO 1982).
} 
4.1.3. Cultures of privacy and the public sphere, of identity and community, of knowledge and economy, of security/insecurity and trust

Particularly in this sense, culture is more than the sum of products of an unclearly differentiated societal area of action, which has specialised in the production of cultural goods, in which "creative artists" work, in arts, music and literature as well as in further branches of this profession. But in this particular sense culture represents more than simply lifestyles or a set of norms, values or convictions. It is rather to be understood as a kind of matrix that reveals areas of meaning, that offers certain possibilities of association (and excludes others), that provides meaningful explanations for distinct patterns of behaviour and interaction, that works by linking together descriptive and prescriptive aspects, thus indicating cognitively correct ("functional”) and normatively correct ("good") behaviour, or better, opportunities of behaviour.

This cultural shaping can also be observed in CULTMEDIA's four areas of research:

I. Which distinct communicating and acting is, can be, may be and should be executed "in private" - i.e., not in public - and which distinct communicating and acting even has a right to be shielded and protected, and where the limits of this shielding and protection are, is culturally coded. Conversely, it is culturally defined and explained which acting and communicating should, may or can be executed "in public", which "public" conduct deserves protection and support (e.g., freedom of assembly) and which does not (e.g., revolt and breach of peace).

II. "Identity", i.e., on the one hand the possibilities of individual identity formation of subjects of action and on the other hand, their consideration or appreciation on the part of social communities or society as a whole, also follows this pattern of cultural coding. As social structures, sexes, professions, background or nationality represent a kind of matrix for the development and formation of distinct ideas and ways of behaving which show a certain degree of stability, but which can also be formed, changed, opened up for new things or shielded against others. The same applies to religious or political convictions (republican, monarchist) or "cultural" forms of expression (e.g., punk, skin) and areas of interest (hacker), identification with a sport (e.g., football fan), with certain teams (e.g., Real Madrid) or athletes, with certain music styles (e.g., reggae), bands, stars or forms of life (e.g., "inhabitants" of a digital town in a "Multi User Dungeon"). In this way we express what we believe in (contents), how we act (conduct) and how we express this (clothes, hair styles, flags, signs of identification), but also the character (aggressive, peaceful, showing solidarity, stressing competition) of the "community" which the individuals with their corresponding subjective identities belong to.

III. As a consequence, culture also influences the "knowledge" of a society, i.e., the forms of knowledge as well as their acceptance as legitimate forms and sources of knowledge, the contents of knowledge as well as their acceptance as valid, correct, true, and ultimately the ways in which it is used. "Acting in economic contexts and with economic goals" is also not at all a culture-free conduct determined by its function, since culture defines its purpose, determines what is of value and benefit, conveys its forms, its patterns (cooperative, competitive, etc.) and what are transferable commodities (goods) and what are not (love, human dignity, public goods).

IV. What is considered as an insecure or secure state is not fixed, but depends on cultural preconceptions. In this way situations and contexts of action are assigned attributes of "insecurity" or "security" to a varying degree, which leads to the 
consequence that one behaves differently (carefully) in these situations or contexts of action. In connection with this, "trust" but also "distrust" represents a necessary resource for any behaviour (intending success). In turn, both are influenced by culture.

\subsection{Technology, media and computer-mediated communication}

For the understanding and the notion of technology - analogous to the notion of culture it is of utmost importance to be positioned broadly and with enough complexity to be able to work on the embedding of technology in cultural processes and the interweaving of technology and culture systematically, on the one hand, with the effects of technical change on culture and, on the other hand, with the influences of culture on technology. The conditions under which media develop and, in turn, become effective are inextricably interconnected with these contexts.

\subsubsection{Cultural contexts: Technological artefacts and technological action}

Common „definitions” of technology are for instance: “[...] technology describes artificial things and procedures which serve practical purposes" (Sachsse 1992: 359). Such formulations - which should be categorised as "understanding of technology in the narrow sense" - see the concrete, "arte-factual" aspect of technology as the central focus. This is rather one-sided, since the question of the origin of technology is not touched on. Technology has not been "given" to man (like nature), it is not - in the original sense of the meaning "natural" and "does not fall out of the blue", but it must be "made", "produced", "created".

Only against this background does it become obvious that technology is not "natural", but "artificial”. In addition, it must be said that specialized technical systems represent the means for the realisation of human purposes. For an appropriate understanding of technology both aspects have to be considered. In such an expanded understanding of technology (notion of technology of a "medium" range) technology includes, first, the quantity of user-oriented, artificial, concrete objects (i.e., the artifacts or technical expert systems), second, the quantity of human action and facilities in which expert systems are created, and third, the quantity of human action in which expert systems are used (cf. Ropohl 1993: 672). If understood in this way, "technology" not only describes the objects made by man ("artifacts"), but also includes their creation and utilisation connections ("contexts") (i.e., the aspects of "having been made", "been applied" or "been used"). Thus technology is not considered to be something static but belongs to an area with genesis, dynamism and change (cf. Banse 1999).

If we now consider that in the contexts mentioned, different conditions (especially of individual, scientific-technological, economical, legal, political, ecological and ethical nature) are of influential importance, it first becomes obvious that by means of this "broad(er) understanding”, technology, if understood not as an isolated, autonomous area that seems to constitute an objective reality, becomes a "social" phenomenon in terms of its development which is insolubly linked ("networked") with the individual and society, with politics and economy. Second, it must be understood that technology "finds its application and everyday use [...] in a socio-cultural context, in a context of collective interpretations and explanations" (Hörning 1985: 199). The starting point is the understanding that technical objects do not necessarily have to be the way they are, and the way they are omnipresent to us, i.e., how they reach our everyday life from autonomous technical conditions. In their creation as well as in their technical use, expert systems are an expression of both, own intentions and purposes and those of others. Despite all exactly installed and registered instructions for action, which promise the optimum utilisation of the function especially for the layman, particularly everyday technology often offers tremendous freedom of utilisation, too: taken up by one, 
badly used by another, ignored by a third person - but always against the background of certain utilisation expectations, influenced by evaluation and advertising as well as embedded in certain societal and technical "infrastructures". The "usefulness of technology is always also something interpreted culturally" (Hörning 1985: 200). Thus it becomes obvious that culture considerably influences the implementation and diffusion of technical solutions via the people "carrying” it, by e.g., using or not using (refusing) it for the realisation of purposes, by forcing modifications, improvements, adaptations and by creating "regulations" for the behaviour of man-technology-interactions. Therefore, in CuLTMEDIA questions should be asked regarding the degrees of cultural freedom in the reception and during the handling of technology in everyday life, and also regarding the fact how different groups and generations with different ways of life and cultural orientations handle offers of technology. These offers of technology maybe but do not necessarily have to be identical.

\subsubsection{Media: Their technological and their socio-cultural side}

One difference in orientation running through the media discourse is to understand media rather as technical systems on the one hand, or as socio-cultural practices on the other hand. However, for CultMediA's intention it is important to consider both the technical and the socio-cultural side of the media since in their interactions lies one of CULTMEDIA's relevant reference problems. In order to develop an adequate understanding of media for CULTMEDIA in this sense, it is important to search the various technical media concepts and to clear up conceptional one-sidedness.

For the main question regarding the relationship of new media and culture - as generally in discourse on technology and society - the question arises as to what extent societal or cultural changes are necessarily anchored in technology itself ("required" by technology as so-called adaptation services) or, vice versa, to what extent changes are dependent on social and cultural practices into which technology is integrated as a means. While processing these questions we have to be aware of the tendency that there exists the danger of oversimplifying our considerations following the one or the other of two - too one-sided - conceptualisations. Regarding the (new) media a (rather) media-theoretical and a (rather) communicationtheoretical one-sided conceptualisation can be distinguished (cf. Rammert 2000). ${ }^{6}$

Both conceptualisations are illustrated in media reality. For CULTMEDIA's project, a decision in favour of one of the perspectives is neither useful nor necessary. They can be emphasized as two different and from case to case heuristically useful conceptions of the dynamism of socio-cultural change inherent in the relationship of media and culture. ${ }^{7}$

\footnotetext{
${ }^{6}$ The media-technical concept is based on the line of thought that the medium itself changes the relationship of man to the world independent of its use. The exaggeration of this line of thought is: every medium creates another view of the world. In this exaggeration lies a highly simplified understanding regarding the connection of media and communication, namely that every new media technology leads to another way of communication and supersedes the old forms of communication. The communication-theoretical concept results from the exaggeration of the line of thought that the medium is a neutral means which opens up new possibilities and that it is only up to the human actors and their actions how communication and interaction relationship change through the use of the media. This line of thought reduces the reality of the media to the handling of tools.

${ }^{7}$ One-sidedness can be avoided when analytically subsequent levels of dialectics of media structures and media practices, which were proposed by Werner Rammert, are considered equal and in their interactions (cf. Rammert 2000: 125; transl.): (a) the media "as material carriers with specific reference to the human senses and to the physical environment, to temporal and spatial dimensions"; (b) the technical forms, "as they are concretely constructed in technical projects, configured in their material, physical and symbolic elements and installed in their context"; (c) the institutionalised forms "how they are legally and technically standardised regarding their functioning and their handling"; (d) the programmes, "the functions and services offered"; (e) the practices, the way in which manufacturers, providers, operators and above all users handle the media”.
} 
Medium means central part, mediating element. In communication science it describes deduced from this - an agency for mediating information. Thus media are mediation systems for information of all kinds (news, opinions, entertainment). Their function is the transport of contents during which specific restrictions of the medium may affect the form of the content. Technical means of communication (e.g., in the form of information and communication technology) serve for the transmission, storage and distribution of information. ${ }^{8}$

An important differentiation in the connection of media and technology is that between primary media for the functioning of which the use of technology is not necessary (e.g., theatre), secondary media for the functioning of which the use of technology is necessary as far as production is concerned, but not for reception (e.g., daily newspaper), tertiary media for the functioning of which the use of technology is necessary for both sides, i.e., for both production and reception (e.g., record). In addition, there are quaternary media for the functioning of which besides technical support of production and reception, the technical mediation of the distribution is indispensable (online media, which are suitable for dissolving the conventional receiver/sender relationship) (cf. Faulstich 2000: 21).

As a working definition, media are described in this context as those socio-technical systems and cultural practices of the dissemination and storage of information which serve for the design of communication and interaction and thus influence the collective as well as individual perception and the building of experiences in the real world. As another temporary classification, new media describe those media whose technical foundations are based on digitalisation, miniaturisation, data compression, networking and convergence.

\subsubsection{Digital media: Their convergence and the genesis of a ubiquitous communication system}

With regard to the understanding of media as "channels", about twenty individual media can be differentiated today (following Faulstich 2000: 22), namely - in alphabetical order books, computer, internet/DVD, journals, letters, magazines/pamphlets, newspapers, sheets of paper, sound radio and television.

The "old" media were once "new", too. Therefore, the category new media should be characterised substantially beyond the aspect of their general everyday use which is still to come. Furthermore, a suitable notion is to be included in this substantial characterisation, which clarifies what is meant by new media in CULTMEDIA's narrow research context. ${ }^{9}$ Without a current satisfactory solution for this task, the fundamental importance of convergence should be stressed in this matter.

Against the background of this medial convergence, CultMediA is focusing its investigations on the relationship of cultural diversity and new media on the internet. Currently the internet is not only the dominating and most dynamic element in the area of new

\footnotetext{
${ }^{8}$ If one searches for a common denominator in media-scientific literature, it can be found in the fact that media serve for the storage and representation of information and the mediation of communication. Communication is usually understood as an exchange of information between individuals, which is based on mutuality and interaction, whereas information is understood as a process in only one direction. Neither informing nor communicating is necessarily modelled as simple (linear) "sending and receiving". Messages should not only be considered as physical events, but must also be understood as "coding” and "decoding”, i.e., as interpretative acts in a social "environment" and against a cultural "background".

${ }^{9}$ Regarding the aspect of their material carriers or their object area the new media can be roughly delimited as an area of microelectronically based hardware and software technologies. "The heart of these technologies are highly efficient computers of various forms the peculiarity of which is, among other things, that they are not limited to working in isolation, but that they can be linked almost without restriction both locally [...] and regionally and ultimately worldwide, and, at the same time, allow equal mutual exchange ('interactivity'). Consequently these devices become an aid for individual and transindividual communication in all spheres of society” (Boehnke et al. 1999: 9; transl.).
} 
media, but it is the element with quantitatively and qualitatively the most far-reaching consequences of socio-political, social-cultural and socio-economical nature.

Internet means "interconnected networks". It is a combination of computer sub-networks in which digital data is exchanged in the form of packages (TCP/IP). The internet connects more or less autonomous computers for the purpose of exchanging data. The universality of the computers characterises the network and gains a new spatial-temporal dimension with the global networking. The internet is the synergy of computer and global network integration: a hybrid, partly computer network, partly network computer, partly individualising the user intimately, partly socialising him.

The internet gains its efficiency and its ability to develop from:

- the universality of the computers that constitute it;

- the ability to digitalise all information and treat it as data;

- the efficiency of data exchange in the form of packages;

- the setting of standards that work on all computers;

- the easy handling of the web browsers as a universal computer interface;

- the efficiency of the hypertext technology which is able to embed complex data structures unobtrusively;

- the interactivity of the WWW and the possibility for the user to have a creative input on it;

- the high level of distribution.

Even today the internet modifies, supplements and/or replaces a variety of historically developed cultural techniques: it is a(n)

- individual means of communication (telephone, videophone, email, chat);

- medium of entertainment (film, television, radio, online games, etc.);

- medium of information (newspapers, books, magazines, libraries, databases);

- medium of knowledge processing which - supported by language recognition and synthesis, recognition of (hand)writing and classification of graphic data - leads to a multiplication of intelligence services;

- medium of trade (buying, selling, auction);

- medium of direct distribution of non-material goods (print media, music, films, financial transactions, education, consulting);

- medium of remote control, remote maintenance, remote supervision, i.e., an "integrated computer";

- medium of self-presentation and self-fulfilment;

- medium which modifies the users' spatial-temporal coordinates through its global distribution and its fast data flow.

Formed as an integrated network, the internet is able to integrate all traditional networks (within the framework of their digitalisation) and all newly created networks (UMTS, etc.). Thus the internet qualifies itself as an outstanding means during the analysis of cultural changes which are connected with the emergence of new media. Another reason for CULTMEDIA's focus on the internet in the investigation of the relationship between cultural diversity and new media lies in the importance that is assigned to the internet in public debates, as an engine of societal and as a motivating force of cultural change. 


\subsubsection{Subjects for reflection, characteristics and significance of new media}

In order to be able to better understand the form and importance of cultural transformations which result in connection with the development of the new media, two subjects of reflection should be used, on the one hand, the relationship of "reality and virtuality" and on the other hand that of "space and time". Both subjects of reflection are to be considered systematically, i.e., on all three levels of research of CULTMEDIA as well as its four areas of research. The decisive factor here is that the cultural transformations are not only a consequence of the extended possibilities of communication and symbol processing or of their broader use, but that the new media are mainly characterised by the fact that they change the relationships of virtuality and reality and of space and time and make them available and designable, "rework" them in a complex way to an extent that has been unknown so far. Instead of supporting one-dimensional theses, e.g., that of a "softer" relation to reality through virtuality or a "shrinking" of space through electronic communication, the topic should be what design potential is inherent in the new media to create new conditions, e.g., through the possible access to an enormous reservoir of sources of information and stocks of knowledge at any time and all over the world.

The novelty created by the digital media can be seen in the various possibilities to realise different communication patterns equally well by means of this one medium of convergent new media: 1:1 - one person can communicate with another; $1: n$ - one can turn to many; m:1 - many people turn to one individual; m:n - many people turn to many others. On this basis, new mixed forms are possible, e.g., if in an email to an individual addressee through "CC" a number of people can also read it and thus participate in the sender's community for a particular topic. In this context, the notion of "virtual community" is also of importance, but here the core and the periphery, that means the "brief visitors" of such communities, must be differentiated.

Digitalisation makes it possible to extensively combine data in a new way, because it means the coding of information in discrete sign strings. These, and with them the digitalised information, can then be stored and communicated without any loss, but they can also be taken to pieces and combined and transformed in a different way. In addition to this, it becomes possible to manipulate them almost without any traces, to store them in a practically uncontrollable manner in unknown places and to open them in unnoticed manner. Digital information technology largely detaches the discrete sign strings from the material carrier by storing and transmitting by means of binary encoding. Almost absolute flexibility while handling digitalised information becomes possible. The other side is the emergence of new forms of dependence on technology, e.g., on the latest programme version or technology generation.

The internet, as the basis of online information and communication is - as a global transmission system which changes media development comprehensively - of special interest for CultMediA. Within the media and communication sciences the determination of online media is still disputed. A differentiation between mass, group and individual communication starting with the relationship of production and reception has to be ruled out, because online media detach the "role asymmetry" of sender and receiver. For an investigation, various forms of communication in the internet and the internet services have to be differentiated.

In this context, changes of identities, social relationships and social groups through the internet are of special relevance. In the following part this is to be demonstrated as an example regarding the statement that via internet an interpersonal exchange can take place which is considerably different from personal meetings. For this, the term, "computermediated communication" (CMC) has been established, which so far is employed to mean communication conveyed by text. For differentiating the different aspects of CMC, Nicola Döring refers to the natural basic form of human communication, the face-to-face situation: in 
this situation we are in the same place at the same time (physical co-presence) and exchange verbal and non-verbal messages. Communication media free the interpersonal communication of the restriction (or the pleasure) of co-presence and make it possible to establish contact with people in spatially different places (cf. Döring 1998: 34).

The differentiation between two forms of communication is widespread: time-delayed, asynchronous communication (e.g., letter, email, fax, telegram, message on the answering machine) and simultaneous, synchronous communication (e.g., phone calls, chatting, video conferences). With CMC - especially through emails, newsgroups and WWW sites asynchronous and - particularly through "Internet Relay Chat" (IRC) - synchronous connections are possible. Of special significance and often discussed is the possibility of anonymous communication in the internet.

With synchronous CMC, the communication processes change fundamentally because a virtual level of action comes to fruition. People not only communicate but also interact virtually, e.g., in the game world of the "Multi User Dungeons" (MUDs).

People who do not know each other in the classic sense communicate with each other across national and cultural borders. The anonymous form of communication which is possible through the internet detaches the forms of civility in the communication among the people present. In the chat rooms or newsgroups in the internet, which determine most images of electronic and virtual communities, various groups come together via the topic. Information between a large number of senders and receivers is transported there. The groups react to the lack of civility, which is caused by the anonymity of communication, with their own common rules of conduct (e.g., netiquette or online slang). In the case of business transactions via internet, anonymity and the (non-)binding nature present a problem to which people have reacted by creating technical substitutes for conventional forms of business civility (e.g., electronic "signatures”).

The hypothesis that new possibilities of cultural participation and political organisation result from media development is of special importance to CuLTMEDIA. However, the main emphasis here is often placed on people in the poorer countries of the world and less on the lower strata in the rich countries. Here, an investigation of the internet conducted by James Slevin provides an interesting example, which is, among others, based on theories by Anthony Giddens (cf. Slevin 2000). ${ }^{10}$ This study is particularly interested in the question of how the internet changes the relationship between local activities and the "(inter)action across distance" and how it can be used to better control the influence of globalisation processes on society/societies. Slevin understands globalisation as an "inherent feature of the modern world" the origins of which reach far back from an historical point of view. Globalisation currently causes a new formation of space and time during which action is of central importance across distances. In this context the internet plays an extremely important role because it can make this action much easier.

New media change the cultural importance of spatial nearness and distance. The linked individual grows - according to a widespread opinion - with their interactive and communicative action beyond the borders of the local community and national society and can participate in transnational cultural exchange. The current media development mainly changes the culturally important functions of spatial (but also historical-temporal) nearness and distance, such as in the case of the decoupling of spatial nearness on the one hand, and the formation of cultural communal spirit as well as the assertion of cultural identity on the other

\footnotetext{
10 Giddens sees a close connection between the processes of the increase of spatial-temporal distance, the disembedding of the social systems (the "lifting" of social relationships from fixed interaction connections and their unlimited restructuring across space-time-spans) and the globalisation which is characteristic for the modern age. According to his view, the three processes mentioned were and are basically influenced by the development of the media (cf. Giddens 1990).
} 
hand (keyword "de-territorialisation of culture"): on the basis of the mass media, territorially localised, and at the same time compact cultural traditions can become insularly distributed. Thus the important role which the mass media has played in the social construction of "imagined communities" (including the modern nation-state) for three centuries is changing due to the current impetus for globalisation in the field of the media. Moreover, new media are becoming helpful now for the identity policies of small and specialised kinds of communities and of other culturally relevant social clusters (e.g., new social movements, nongovernmental organisations, transnational concerns and ethnic, sexual and other minorities).

\section{Discursive-comparative research-level: Interactions between cultural diversity and new media}

In this chapter, CultMediA's discursive-comparative research level is dealt with, which comprises further research subjects regarding the topic of "Interactions between cultural diversity and new media". They will be introduced, first, in connection with a discussion of the field of tension of cultural homogenisation and diversification (cf. 5.1.). They will be further explained in connection with the identification of three areas of research and the crosssectional topic; in this respect the comparative analysis of the interaction pattern of cultural diversity and new media will be focused on the complexes given (cf. 5.2.).

Before the interactions between "cultural diversity" and "new media" in their function as an element of European integration can be tackled critically (cf. 6.), they must first be analysed, described and structured. Through this process, their dynamism and their patterns will become critically incorporated.

Qualitative analyses of both the basic cultural conditions and implications as well as the cultural consequences and effects of the new information and communication possibilities, a synonym for the internet, should be the main emphasis of CuLTMEDIA's work. The question of the "culture of the internet", which can be interpreted both in the direction of the basic cultural conditions and processes which have characterised the internet and in the direction of the new cultural forms of network-based communication, which are especially characterised by the internet, represents a continuous interest in knowledge.

\subsection{Homogenization versus diversification}

With regard to the interactions of "cultural diversity” and „new media”, and more precisely, their consequences for "cultural diversity" 11 , it must be assumed that neither the hypothesis of continuous cultural homogenisation nor that of continuous cultural diversification can be proved. In this respect it is rather an area of tension between the poles of which - homogenisation versus diversification - a terrain of complex overlapping and diverse design options is created. The shape of this overlapping depends on how they are designed socially, what contextual conditions (language and cultural differences between the European nations) and what forces act upon it. The form of the interactions of "cultural diversity" and "new media" is not simply determined by the characteristics of the "new media", but also by the way in which optional connections become concrete, under the influence of protagonist coalitions (network operators, content providers, user groups, media and cultural policy) and macrosocietal processes such as (commercial) globalisation, individualisation or reflexive modernisation.

\footnotetext{
11 The reverse direction of the topic, which regards the interactions of cultural diversity and new media as far as their consequences for these media are concerned (“Are they implemented, used, developed differently?”), will only be dealt with in second place.
} 
In the context of the interactions of cultural diversity and new media and their role in the process of European integration it is of special interest to see if and to what extent there are similarities and patterns in the relationship between Eastern and Western Europe or between Northern and Southern Europe, whether similarities and differences form a pattern or if they are distributed in a particular arrangement.

\subsubsection{Intercultural communication/dialogue and cultural heritage/memory}

For the purpose of a further analysis and the preparation of subsequent considerations on the synthesis, it is useful to differentiate between intercultural "communication" on the one hand and intercultural "dialogue" on the other hand. "Intercultural communication" describes communication that takes place between actors who belong to different cultures. "Intercultural dialogue", on the other hand, is understood as a special form of metacommunication, namely communication in which the focus is on "intercultural communication". Intercultural dialogue is characterised by the fact that intercultural communication becomes reflexive, i.e., by the fact that "intercultural communication" becomes an explicit topic in processes of intercultural communication.

Against this background of differentiation the problem that an increase of processes of intercultural communication may lead to increased understanding between the cultures, although this is not necessarily the case, can be looked at. When intercultural communication takes place, it is certainly a prerequisite for the development of mutual understanding and mutual acceptance. However, the fact that intercultural communication takes place is no sufficient reason for the fact that it also happens in this way. It is much more likely to be the case that non-understanding and non-acceptance (nevertheless) prevail or (even) will prevail.

Originally, cultures are related to space or territory because communication processes which build up cultures first only appeal to presence, or more precisely, the accompaniment of interaction processes between co-present actors. Even under these conditions, intercultural communication is possible, but - due to the condition of co-presence - it presupposes the mobility of the actors, meaning their physical movement through space and time. Intercultural communication - as communication between actors of different cultures - becomes (increasingly) easier and less costly if transmitted via media (letters, books, radio, CMC), because these media can bridge space and time (as distances which separate cultures) without having to transport the actors. Instead, statements or, in other words, "messages" are transported (across cultural borders). The more communication takes place in this way across space and time, i.e., bridging the condition of space/time co-presence, the more "intercultural communication" can take place. At the same time, the (media-specific) conditions of the possibility of understanding the contents of intercultural communication processes change with that. Due to the lack of co-presence, common environmental conditions that make interpretation processes easier do not apply. In addition - due to the lack of co-presence - one cannot react directly or ask how something was meant if uncertainties occur regarding the intentions for the action or what was communicatively meant. However, under the conditions of the medium "cyberspace", some of the restrictions of other media do not apply. In the internet people can communicate both with a time delay and simultaneously. With CMC it is possible to create a virtual space of communication that simulates or virtually facilitates space/time co-presence.

What status does "intercultural communication" have in connection with the interactions between "cultural diversity" and "new media"? What course does "intercultural communication" take and what consequences does it have as an exchange process between cultures of the relationship of privacy and the public, cultures of the relationship of identity (formation) and community (building) and cultures of the relationship of knowledge and economy/economies as well as cultures of the relationship of (in)security and trust? 
What status does the topic of cultural memory, cultural heritage in connection with the interactions between "cultural diversity" and "new media” have? Which role do the digital media play for its conservation, for the free access to it, for its use in innovative cultural practices?

"Cultural heritage" and "cultural memory" play an important role for all three subject areas, in the socio-economic area as a non-material source of prosperity and Europe's economical ability to develop ("Knowledge and the Economy"), in the socio-political area regarding the ideals of order and freedom ("Privacy and the Public"), in the socio-cultural area ("Identity and the Community") regarding the hearts of identity formation processes (subjectivity, sense of community, common metaphysical convictions, patterns of interpretation).

\subsection{Interactions of the three research fields including the cross-sectional topic}

Interactions between the (respective) cultures ("cultural diversity") and the "new media" (internet, digital media, multimedia, convergence) take place in all areas of society and in all European countries. In order to be able to identify and analyse them, these interactions are to be investigated intensively and comparatively in three areas and a fourth cross-sectional topic.

\subsubsection{Research field 1: Privacy and the public sphere}

The first research field of CULTMEDIA is called "privacy and the public sphere". In terms of the relationship between cultural diversity and new media the topic here are the conditions of the relationship of privacy and the public sphere, and whether they change through computer-mediated communication. "Privacy" comprises the right of every individual to protect their private sphere. This basic right is a part of the constitutions of modern societies and is expressly recognised in various international agreements. Since the beginning of modern times it has functioned in the sense of a regulatory idea as a basis of social life, interpersonal communication and social interaction. This right results from the interest of the individual in maintaining a space which is supposed to be free of unauthorised inspection and influence through other people, companies, institutions or state organs. A dimension of "privacy" regards the personal conduct and preferences of action in the sense of sexual, religious or cultural practices. In addition, there is the dimension of personal communication conduct when using the respective media and services (telephone, email, chat, etc.)

Finally, there is the dimension of accessing personal data (data protection), for example of a medical and financial nature, which are stored, transmitted and processed digitally. The "public sphere" describes that societal area which, in contrast to the private sphere (the individuals, the family, economic decisions based on private property), should principally be open to all people belonging to a society or which must be open to all members of society as a necessary prerequisite of democracy. The border between private and public sphere is variable. It is subject to historical changes, determined differently in different cultures (e.g., through everyday practice or public opinion) and is fixed through political-legal decrees in one way or another. In addition, it is dependent on the technologies and media that are available and used.

The research field can be outlined through the following points:

- changes in the perception of privacy and the public sphere;

- influence of new media (especially the internet) on the shifting of the understanding of the borders between privacy and the public sphere; 
- influence of the new media on changes in the value system of the individual regarding the relationship of privacy and the public sphere - universalism and particularism;

- possibilities and challenges of digital media regarding the authenticity and trustworthiness of pictures and documents or their sources in connection with their cultural meaning and their influence on the formation of (political) opinions and intentions.

\subsubsection{Research field 2: Identity and the community}

CultMediA's second research field is called "identity and the community". In the context of cultural diversity and new media, the problem here is the changing pattern of individual identity formation (in the relationship of personal and social identity) as well as the formation of communities (as an association of people who live together, interact or communicate with each other). Of further interest is the release of the spatial-temporal neighbourhood, to, as a consequence, changed norms of conduct as well as to changed forms of inclusion and exclusion and mainly to the question whether they lead to any consequences for the social differentiation and cultural diversity.

The research field can be outlined by the following aspects:

- effects of development and introduction of technologies of computer-mediated communication (CMC) (internet, WWW), digital media (DM) (digital photo- and videography) and those for the creation of virtual realities (VR) on communication, interaction and perception processes, cultural practices and the way we see ourselves and reality;

- the question how the use of these media and technologies changes the currently practised (experienced, seen, created) relationship of virtuality and reality (perception, representation, construction, simulation, deception, space/time subject) and our (everyday, lifeworld/professional, scientific-technological/and philosophical, reflexive) understanding of these conditions;

- problem of determining the significant - differentiating - characteristics of "computer-mediated communication" (CMC), digital media (DM) and "virtual reality" (VR) technologies within the framework of their application and use, especially in comparison with the use of analogous technologies (fax, telephone, telegraphy) as well as mass-medial communication (radio, cinema, television), of written communication (letters, books, newspapers) and the real-world "face-toface” communication (spoken, written, visual and hypermedial communication / uni-, bi- and multimedial communication);

- changing patterns of individual identity formation (ano- and pseudonymisation; presentation of changed physical, sexual, personal, ethnic and social characteristics) through the use of the internet and the media (cyberidentity) and their consequences for interpersonal and social relationships (delimitation or continuation in "real life" (RL); opening of communication or narcissistic and autistic tendencies, etc.);

- changing patterns of collective identity formation (digital citizenship) and building of new communities (virtual communities) through the use of the internet and the media (centralisation of interests; affectual components; untying of the spatial-temporal neighbourhood; norms of conduct; inclusion and exclusion) as well as their consequences for the social differentiation and the cultural diversity in general (sub-cultural, ethnic, regional and national identities; varieties in languages). 


\subsubsection{Research field 3: Knowledge and the economy}

CULTMEDIA's third research field is called "knowledge and the economy". In the context of cultural diversity and new media, the problem addressed here is the changing interaction of conduct which creates (scientific) and uses (economic) knowledge. To the extent of how specific differences exist in the culturally defined obstinacy of activities in these two fields of conduct, it can be expected that they change in a different manner in the wake of computermediated communication and globalisation. The increase in cultural reflexivity and relativisation of cultural characteristics through increased possibilities of comparison is of major importance here, too. In addition, globalisation processes increase the degree of networking of the activities included in globalisation processes, the culturally defined obstinacy of which changes through this to a greater or lesser extent.

The research field can be outlined by the following aspects:

- consequences of the convergence of electronic data processing technologies (computer) and computer-mediated communication (internet) for the societal (socio-economic, cultural) connections, forms and procedures of the handling of information and knowledge;

- relationship of the processes of information processing, storage and transmission and those of knowledge creation and provision, especially regarding the transfer of knowledge in science, economy and society as well as its use and exploitation (private - commercial);

- determination of knowledge in this context (definitions and conceptions of nature and functions; relationship between information and knowledge; knowledge as potential for action, differentiation of forms: cultural knowledge - scientific knowledge - professional knowledge - user knowledge; orientational knowledge versus instrumental knowledge, etc.); characteristics of changed forms of knowledge or a general change of form (acceleration of increase in knowledge and its devaluation; contextualisation);

- shifts in the relationship of the production factors knowledge, work, capital and nature - what makes knowledge the non-material key factor for the development of a European knowledge-based society;

- knowledge as a good versus knowledge as a common property (rights of ownership and use; copyright, patents);

- relationships between cultural knowledge and cultural diversity; consequences, problems and perspectives of the digitalisation in the context of preserving, passing on and accessing cultural heritage (cultural memory, cultural heritage) (education, libraries, museums, conservation of monuments).

\subsubsection{Cross-sectional topic: Security/insecurity and trust}

The research problem of the cross-sectional topic "security/insecurity and trust", which is at the same time the fourth research field of CULTMEDIA, concerns the changed balance of these two fundamental parameters for the constituency of modern societies, particularly since this problem unfolds in a special way in the intersectional plane of the three research fields mentioned above.

Every use of technology presupposes trust, for example regarding fulfilment of function, realisation of goals and availability. Here, trust can refer to individual people or more comprehensive social institutions and systems. While trust compensates the insecurities connected with every step, possibilities of conduct are opened up which would not have 
existed without this trust. In the German language, the word Sicherheit, which can be translated as security, is used in at least three senses (cf. Kaufmann 1970): security as a feeling of safety, as self-confidence and as system security (of means for various purposes which can be manufactured and calculated). All three uses are relevant for CULTMEDIA, since they refer to those human creations which are called new media. Thus the cultural way in which a society sees itself must be made the central topic, including its "understanding of security" (need for security, experience of insecurity, safety provisions, communication on possible advantages and disadvantages or "profits" and "losses"). In this process, the limit is fixed regarding the time and context-dependent acceptable and accepted conduct which uses technology (e.g., regarding the expenses for securing, the relationship of cost and benefit or the simplicity of handling), the stepping over of which may lead to individual or institutional "defence reactions" (refusal, inefficient use, reverting to conventional solutions, etc.). Beyond the individual need and desire for security, various social groups have developed different ways of handling insecurities, dangers and risks caused by technology. A solution to the problems related to individual and subjective needs for security can only lie in the development of appropriate security cultures in the irresolvable field of tension between individual and society.

This research field can be outlined by the following aspects:

- balance between the technical, legal, etc. measures for the protection of privacy and those for the protection of the public sphere;

- the problem of data protection and the measure of real risk; possible abuse of personal data and possible manipulation regarding the identity of people;

- internet culture and requirements for data protection and privacy;

- culture and insecurity - vulnerability of the modern-day infrastructure, with the internet serving as an example;

- consideration of the handling of questions of e-security within the area of the new media - security "cultures" in the narrow sense - by comparing countries and cultures;

- internet culture and requirements for data protection and privacy, the clear identification of the borders between the right of the individual to information and the right to privacy; censorship in the internet versus free access to complete information;

- culture and insecurity - vulnerability of modern-day infrastructures with the internet serving as an example; consideration of the handling of e-security questions within the surroundings of the new media - security "cultures" in the narrow sense - by comparing countries and cultures.

\section{Synthetic-conciliar research level: Elements of European integration}

By means of comparative investigation of the interactions of cultural diversity and new media in selected research fields, not only the patterns of the respective interactions are to be identified, but it should also be investigated to what extent this pattern varies when comparing European nations. Instead of "only" leading a general discussion on cultural diversity as an element of European integration, debating, e.g., if diversity should be understood as a strength or a weakness, the question of the connection between cultural diversity and new media is investigated in a particular way in the context of four concrete complexes, which are of special importance for the development of the present European society/societies and the progression of the EU integration processes. 
The central matter of concern of CULTMEDIA's "third” synthetic-conciliar research level is consequently to investigate the role of these interactions as an "element of European integration". In this context, first the importance of "cultural identity" (national identities European identity) for the process of European integration has to be clarified, particularly in connection to its (respective) political and economic contextual conditions (cf. 6.1.). Second, the task is to draw conclusions from the comparison of the interaction patterns between cultural diversity and new media mentioned above from the selected research fields (cf. 6.2.). Finally, against this background, recommendations are to be developed for the further formation of the media and cultural policies of the EU and its member states. The problem in this context is not the coherence of its guidelines, but also the starting points and instruments as well as the question of whether, within the framework of the latest European expansion, there is a special need for action and what measures can meet this (cf. 6.3.).

\subsection{Considerations}

Any discussion of questions regarding the connection of cultural diversity, new media and European integration presupposes an examination of the importance of "Europe". ${ }^{12}$ Is this the name of a geographical place? A vision of the perfect civilisation? Or a cluster of interacting states which influence each other? At first glance it seems simple to decide in favour of none of the alternatives: Europe is a concept which is open to interpretation. In European history, "Europe" has adopted a number of different meanings and various preferences have been articulated. Especially for the present, which is in many ways characterised by radical changes and new departures throughout the world, it has to be assumed that "Europe" represents a changing concept.

An expression of the changing concept of "Europe" is the formulation of far-reaching and ambitious European-political development objectives, as, e.g., in the declaration of the Lisbon European Council of March 2000: „The Union has today set itself a new strategic goal for the next decade: to become the most competitive and dynamic knowledge-based economy in the world, capable of sustainable economic growth with more and better jobs and greater social cohesion” (European Council 2000).

Economic growth, employment, social cohesion, quality of life, and sustainable development can all be viewed as crucial aspects of a $21^{\text {st }}$ century European model the EU is striving for. Taking into account Europe's diversity in this context is itself a feature of a specific European way of socio-economic development.

In the context of this European development model - that is also oriented towards similar ideas from the OECD (cf. Hodgson 2000) - the technology-driven transformation process to a "knowledge-based society" is seen as the pacemaker. However, with the stress on "social cohesion" and "sustainability" a specifically European point is emphasised. Europe's cultural diversity plays an ambivalent role in this context. On the one hand it is considered as a problematic condition and obstacle for the further economic development of the entire common area. On the other hand it is considered to be a special strength because it bears considerable innovation potentials and provides, with the non-material economic factors "culture" and "knowledge", those resources whose value increases in a "knowledge-based society" in comparison with the other factors of productivity (capital, work, nature; cf. Stehr 1994). In this context CultMEDiA sees it as its task to explicitly make the problem area of "cultural identity”, "cultural diversity" and "European integration” its central topic, and this in

\footnotetext{
${ }^{12}$ Here CultMediA is trying to link up with the debates and results of two research projects, which have been funded and carried out within the framework of the European Science Foundation (ESF): "European identity European diversity" (an ESF workshop project) and "Changing Media - Changing Europe” (an ESF scientific network) (cf. http://www.esf.org).
} 
connection with those new information and communication technologies that are considered the pacemakers of the "knowledge-based society".

The importance of this task is also emphasised by one of the most recognized newsletters of the European Science Foundation (ESF), which discusses the scientific-political and programmatic objectives of the Sixth Framework Plan of the EU commission; it says "Perhaps the unique and most self-evident contribution which the human sciences in Europe can make at this time concerns cultural identity, diversity and integration: namely for a sustainable European Union" (ESF 2002: 4). Furthermore, it states that "Within the context of the multicultural European Union and the future plans to fully integrate countries applying for accession, knowledge about and understanding of cultural identity, diversity and integration is vital to a successful integration process; for cultural change occurs on a different timescale, and often out of step with more rapid social and economic change” (ESF 2002: 4).

\subsection{Conclusions}

The following section provides some conclusions regarding the question of the role that the interaction patterns of cultural diversity and new media - especially in the areas of privacy and the public sphere, identity and the community, knowledge and the economy as well as security/insecurity and trust - play as elements of European integration.

The starting point is that the interactions of cultural diversity and new media as "elements" of European integration mentioned might play a contradictory role. Their ambivalence lies in the fact that they are suited to drive integration processes, but they are also connected with challenges which - if not mastered - can block integration processes or even cause disintegration processes.

In order to clarify these connections and to elaborate on results, CULTMEDIA discuss the following main questions:

1. Are these interaction patterns (for each of the topics 2, 3 and 4 plus the cross sectional topic 5) in the different European countries (in particular those of the participating research partners) similar or dissimilar to each other?

2. Can these (dis)similarities be distributed according to a geographic cultural area east/west or north/south pattern?

3. Do signs of a progressing "homogenisation" of European cultures result from the comparison of the interaction patterns and their possible distribution or do they indicate an increasing cultural "diversification”?

4. What can be deduced from the interaction patterns identified in the three plus one areas for the role of the new media in the process of European integration (under particular considering the latest European expansion)?

\subsection{Recommendations}

If the task is now to develop recommendations for the further shaping of the European media and cultural policies, this is done under the restriction that only the guidelines themselves constitute the topic and not the elaboration of explicit suggestions for the implementation of concrete single measures. Moreover, it is intended to illustrate the consequences regarding the guidelines from the research results and the conclusions drawn, especially regarding the shaping of the new information and communication media, particularly the internet. If in this context "cultural diversity" is used in the sense of a state worth preserving, this is done from a higher European perspective. The variety of different ethnic-national and language-related cultures is to be preserved. But what does this mean for the respective ethnic-national and language-related culture that is addressed as a unit in this 
variety? What does diversity mean from the respective national perspective? Does it mean conserving the national culture? Promoting its further development through intensified intercultural communication and the expansion of intercultural dialogues, even at the expense of its levelling during the mutual penetration of the European cultures?

In order to carry out a new, extended intercultural dialogue, new, extended communicative, media-related and cultural competences are needed. A central requirement is to learn how to cope appropriately with the growing extent and the increasing speed of present processes of change and their consequences.

In mixed-national internet "communities" - the hypothesis can be formulated in this way - there are good prerequisites for the expansion of intercultural communication in the sense of intercultural dialogue. In such transcultural spaces there are opportunities to further develop communicative, media-related and (inter)cultural competences simultaneously or combined with each other.

In order not to lose the chances of the information society both the homogenisation and differentiation tendencies are to be considered adequately and used as opportunities for shaping the European future.

\section{Outlook: Pursuits and wishes}

The complexity and dynamics of the "quadratic" relationship of the intensive and farreaching interactions of culture, society, technology, and the media is not only of major importance for Europe's future. It has also resulted in a research field that goes "beyond" the disciplinary specialisations of individual experts. In addition to this, developing such a project also needs intercultural cooperation.

The European research-network CultMediA, whose design has been presented here, embraces at present 16 partner-institutes out of 11 different European countries. During the seven years of the network's existence, an increasing convergence is recognizable among the methods and theories that determine the research-practice of all participants. Moreover, one can perceive an increasing interdisciplinary consciousness as against the leading questions and focal problems of the network. In order to strengthen the network and its research capacities, more partners are needed in order to incorporate them into the consortium. New elements of the net are desired and necessary in order to enlarge the theoretical as well as empirical basis of the investigations. Interested research-groups and competent (single) persons are friendly invited to take part and contact us.

In the context of CultMedia and the activities of its partners a series of meetings and conferences have been organized and realised so far, among others in Berlin (D), Prague (CZ), Potsdam (D), Banská Bystrica (SR), Katowice (PL), Budapest (H), San Sebastián (E) and Klagenfurt (A). The proceedings of these reunions have been published already or are about to be published. ${ }^{13}$ Currently, the network is occupied with several activities focusing on the realization and specification of its investigational tasks in the following areas of research:

(a) in the context of CULTMEDIA's research on "knowledge and the economy": "media-education and media-competence" (with a leading role of the network-node Katowice) and "e-administration” (with a leading role of the network-node Cottbus);

\footnotetext{
13 Published results (as a selection) are the following: Banse 2003, 2005; Banse and Bartiková 2004, 2006; Banse and Kiepas 2008; Banse, Winter and Wieser 2009; Fleissner and Romano 2006; Galántai, Petsche and Várkonyi 2006; Hauser 2010; Kiepas, Sułkowska and Wołek 2009; Kiepas, Szczepański and Żydek-Bednarczuk 2006; Kiepas and Żydek-Bednarczuk 2006; Petsche 2005; Petsche and Zapf 2008; Petsche, Zapf and Köhler 2007; Ursua and Metzner-Szigeth 2006; Ursua, Metzner-Szigeth and Gonzáles 2011.
} 
(b) in the context of CULTMEDIA's research on "(in-)security and trust”: „security-cultures“ (with a leading role of the network-nodes Karlsruhe and Wuppertal; cf. e.g., Banse/Hauser 2008a, 2008b)

(c) in the framework of the ongoing debate about the common grounds of all of CULTMEDIA's research fields:

"theoretical foundations", above all concerning the description of the general relations of culture and technology as well as the general characterisation of the information-society (with a leading role of the network-nodes Karlsruhe, Münster and Potsdam; cf. e.g., Metzner-Szigeth 2005, 2006, 2007, 2008).

Currently the European research network CuLTMEDiA undergoes a process of consolidation. CULTMEDIA is engaged in the ignition of bi- and multilateral research-projects, in the exchange of scientific stuff, and in the promotion of young scientists.

\section{References}

Appadurai, Arjun 1996 Modernity at Large. Cultural Dimensions of Globalization (4 ${ }^{\text {th }}$ ed.). Minneapolis: University of Minnesota Press.

Banse, Gerhard 1999 Die Verbindung “wahrer Grundsätze” und “zuverlässiger Erfahrungen”. Zur Möglichkeit und Wirklichkeit von Allgemeiner Technikwissenschaft nach Johann Beckmann. In: Günter Bayerl and Jürgen Beckmann (eds.), Johann Beckmann (1739-1811). Beiträge zu Leben, Werk und Wirkung des Begründers der Allgemeinen Technologie, 329-350. Münster: Waxmann.

Banse, Gerhard (ed.)

2003 “Cultural Diversity and New Media.” Thematisches Heft der Zeitschrift Teorie Vědy.

Časopis pro teorii vědy, techniky a komunikace/Theory of Science. Journal for Theory of Science, Technology \& Communication, vol. 24, no. 1.

2005 Neue Kultur(en) durch Neue Medien (?). Das Beispiel Internet. Berlin: trafo.

Banse, Gerhard and Monika Bartíková (eds.)

2004 "E-Learning Issues.” Thematisches Heft der Zeitschrift Teorie

Vědy. Časopis pro teorii vědy, techniky a komunikace/Theory of Science. Journal for Theory of Science, Technology \& Communication, vol. 25, no. 3.

2006 e-Learning? - e-Learning! Berlin: trafo.

Banse, Gerhard, Armin Grunwald and Michael Rader (eds.) 2002 Innovations for an e-Society. Challenges in Technology Assessment. Berlin: edition sigma.

Banse, Gerhard and Robert Hauser

2008a Technik und Kultur. Das Beispiel Sicherheit und Sicherheitskultur(en). In: Olga Rösch (ed.), Technik und Kultur, 61-83. Berlin: News \& Media / Marcus v. Amberg.

2008b Technik als (Intra- und Inter-)Kulturelles. Exemplarisches. In: Norbert Gronau and Walter Eversheim (eds.), Umgang mit Wissen im interkulturellen Vergleich. Beiträge aus Forschung und Unternehmenspraxis, 49-77. Stuttgart: Fraunhofer IRB.

Banse, Gerhard and Andrzej Kiepas (eds.) 2008 Visionen der Informationsgesellschaft 2016. Berlin: trafo.

Banse, Gerhard, Christian J. Langenbach and Petr Machleidt (eds.) $2000 \quad$ Towards the Information Society. The Case of Eastern European Countries. Berlin/Heidelberg: Springer.

Banse, Gerhard, Rainer Winter and Matthias Wieser (eds.) $2009 \quad$ Neue Medien und kulturelle Vielfalt. Konzepte und Praktiken. Berlin: trafo.

Beck, Ulrich 1997 Was ist Globalisierung? Frankfurt am Main: Suhrkamp. 
Boehnke, Klaus, Werner Dilger, Stephan Habscheid, Werner Holly, Evelyne Keitel, Josef Krems, Thomas Münch, Josef Schmied, Martin Stegu and Günter Voß. 1999 Neue Medien im Alltag: Von individueller Nutzung zu soziokulturellem Wandel. Lengerich: Pabst Science Publishers.

Döring, Nicola 1998 Sozialpsychologie des Internet. Göttingen: Hogrefe.

European Council 2000 Presidency Conclusions, Lisbon Summit, March 23-24, 2000. - URL: http://www.europarl.eu.int/summits/lis1_en.htm [03.03.2004].

European Science Foundation (ESF) 2002 Reflections. (Newsletter of the Standing Committee for the Humanities, 6.) Strasbourg.

Faulstich, Werner $2000 \quad$ Medium. In: Werner Faulstich (ed.), Grundwissen Medien (4 ${ }^{\text {th }}$ ed.), 21-108. München: Wilhelm Fink.

Fleissner, Peter and Vicente Romano (eds.) 2006 Digitale Medien - Neue Möglichkeiten für Demokratie und Partizipation? Berlin: trafo.

Fuchs, Max 1999 Mensch und Kultur. Zu den anthropologischen Grundlagen von Kulturarbeit und Kulturpolitik. Opladen: Westdeutscher Verlag.

Galántai, Zoltán, Hans-Joachim Petsche and László Várkonyi (eds.) 2006 Internet Security. Facetten eines Problems. Berlin: trafo.

Gehlen, Arnold 1958 Der Mensch. Seine Natur und seine Stellung in der Welt (6 $6^{\text {th }}$ ed.). Bonn: Athenäum.

Giddens, Anthony 1990 The Consequences of Modernity. Stanford, CA.: Stanford University Press.

Grunwald, Armin, Gerhard Banse, Christopher Coenen and Leomhard Hennen 2006 Netzöffentlichkeit und digitale Demokratie. Tendenzen politischer Kommunikation im Internet. Berlin: edition sigma.

Habermas, Jürgen

1981a Theorie des kommunikativen Handelns. Bd. 1: Handlungsrationalität und gesellschaftliche Rationalisierung. Frankfurt am Main: Suhrkamp.

1981b Theorie des kommunikativen Handelns. Bd. 2: Zur Kritik der funktionalistischen Vernunft. Frankfurt am Main: Suhrkamp.

1989 The Structural Transformation of the Public Sphere. Cambridge, MA/London: Massachusetts Institute of Technology.

Hauser, Robert 2010 Technische Kulturen oder kultivierte Technik. Das Internet in Deutschland und Russland. Berlin: trafo.

Hermeking, Marc 2001 Kulturen und Technik. Techniktransfer als Arbeitsfeld der Interkulturellen Kommunikation. Beispiele aus der arabischen, russischen und lateinamerikanischen Region. Münster: Waxmann.

Hodgson, G. M. $2000 \quad$ Socio-economic Consequences of the Advance of Complexity and Knowledge. In: OECD (ed.), The Creative Society of the 21st Century, 89-112. Paris: OECD.

Hörning, K.-H. 1985 Technik und Symbol. Ein Beitrag zur Soziologie alltäglichen Technikumgangs. Soziale Welt, vol. 36, no. 2, 185-207.

Kaufmann, Franz-Xaver 1970 Sicherheit als soziologisches und sozialpolitisches Problem. Untersuchungen zu einer Wertidee hochdifferenzierter Gesellschaften. Stuttgart: Enke.

Kiepas, Andrzej, Mariola Sułkowska and Magdalena Wołek (eds.) 2009 Człowiek a światy wirtualne 
[Human and virtual Reality]. Katowice: Verlag der Schlesischen Universität.

Kiepas, Andrzej, Marek S. Szczepański and Urszula Żydek-Bednarczuk (eds.) 2006 Internet -

Społeczeństwo informacyjne - Kultura [Internet - Global Communication - Identity]. Tychy: Verlag der Hochschule für Wirtschaft und Sozialwissenschaften.

Kiepas, Andrzej and Urszula Żydek-Bednarczuk (eds.) 2006 Informationsgesellschaft und Kultur. Internet - Globale Kommunikation - Identität. Berlin: trafo.

King, Anthony D. 1993 Introduction. Spaces of Cultures, Spaces of Knowledge. In: Anthony D. King (ed.), Culture, Globalization and the World-System. Contemporary Conditions for the Representation of Identity, 118, Binghamton, NY.: State University of New York.

Klein, Hans-Joachim 2000 Kultur. In: Bernhard Schäfers (eds.), Grundbegriffe der Soziologie (6 ${ }^{\text {th }}$ ed.), 196-199. Opladen: Leske + Budrich.

Kroeber, Alfred L. and Clyde Kluckhohn 1952 Culture. A Critical Review of Concepts and Definitions. Cambridge, MA: Vintage Books.

Langenbach, Christian J. and Otto Ulrich (eds.) $2002 \quad$ Elektronische Signaturen. Kulturelle Rahmenbedingungen einer technischen Entwicklung. Berlin/Heidelberg: Springer.

McIntosh, Donald 1997 Language, Self, and Lifeworld in Habermas's Theory of Communicative Action. In: Reymond Boudon, Mohammed Cherkaoui and Jeffrey C. Alexander (eds.), The Classical Tradition in Sociology. The European Tradition. Vol. IV: European Sociology in the Twentieth Century: From PostIndustrialism to Post-Modernism, 102-130, London/Thousand Oaks/New Delhi: Sage.

Metzner-Szigeth, Andreas

2005 Knowledge, Computer-Mediated Communication and Sustainable Development. In: Gerhard Banse, Imre Hronszky and Gordon Nelson (eds.), Rationality in an Uncertain World, 251-261. Berlin: edition sigma.

2006 “El movimiento y la matriz” - Internet y transformación socio-cultural. Revista Iberoamericana de Ciencia, Tecnología, Sociedad e Innovación (CTS+I), no. 7, - URL: http://www.campus-oei.org/revistactsi/numero7/articulo04.htm.

2007 Internet \& Gesellschaft: Ein Humanes Projekt? Sic et Non - Zeitschrift für Philosophie und Kultur - im Netz, no. 8, -

URL: http://www.sicetnon.org/content/pdf/internet\&gesellschaft.pdf.

2008 Von Cyber-Identitäten, virtuellen Gemeinschaften und vernetzter Individualisierung - sozial-psychologische Überlegungen. Sic et Non - Zeitschrift für Philosophie und Kultur - im Netz, no. 9, - URL: http://sicetnon.org/content/pdf/cyber-ident.pdf.

Paschen, Herbert, Bernd Wingert, Christopher Coenen and Gerhard Banse 2002 Kultur-Medien - Märkte. Medienentwicklung und kultureller Wandel. Berlin: edition sigma.

Petsche, Hans-Joachim (ed.) 2005 Kultur und/oder/als Technik-zur frag-würdigen Medialität des Internets. Berlin: trafo.

Petsche, Hans-Joachim and Antje Zapf 2008 Die Neuen Medien und die kulturelle Vielfalt Europas. Eine empirisch vergleichende Erhebung unter Studierenden Deutschlands, Polens, Spaniens, Tschechiens und Ungarns (unter besonderer Berücksichtigung des Internets). Berlin: trafo.

Petsche, Hans-Joachim, Antje Zapf and Thomas Köhler 2007 Die Neuen Medien und die kulturelle Vielfalt Europas. Empirisch-vergleichende Erhebung unter Studierenden Deutschlands, Polens, Spaniens, Tschechiens und Ungarns. 2 vols. Berlin: trafo

Rammert, Werner $2000 \quad$ Virtuelle Realitäten als medial erzeugte Sonderwirklichkeiten. Veränderungen der Kommunikation im Netz der Computer. In: Werner Rammer (ed.), Technik aus soziologischer Perspektive II, 115-128. Opladen: Westdeutscher Verlag. 
Robertson, Roland 1998 Glokalisierung: Homogenität und Heterogenität in Raum und Zeit. In: Ulrich Beck (ed.), Perspektiven der Weltgesellschaft, 192-220. Frankfurt am Main: Suhrkamp.

Ropohl, Günter 1993 Technik. In: Brockhaus-Enzyklopädie, Vol. 21, 672-674. Mannheim: Brockhaus.

Sachsse, Hanns 1992 Technik. In: Helmut Seiffert and Gerard Radnitzky (eds.), Handlexikon zur Wissenschaftstheorie, 358-361. München: Ehrenwirth.

Schmidt, Siegfried J. $2000 \quad$ Kalte Faszination. Medien, Kultur, Wissenschaft in der Mediengesellschaft. Weilerswist: Velbrück.

Slevin, James 2000 The Internet and Society. Cambridge: Wiley-Blackwell.

Stehr, Nico 1994 Knowledge Societies. London: Sage.

trafo Verlagsgruppe Dr. Wolfgang Weist. - URL: http://www.trafoberlin.de.

UNESCO 1982 Mexico City Declaration on Cultural Policies. World Conference on Cultural Policies. Mexico City, 26 July - 6 August 1982 - URL:

http://portal.unesco.org/culture/en/files/12762/11295421661mexico_en.pdf/mexico_en.pdf.

Ursua, Nicanor and Andreas Metzner-Szigeth (eds.), $2006 \quad$ Netzbasierte Kommunikation, Identität und Gemeinschaft/Net Based Communication, Identity and Community. Berlin: trafo.

Ursua, Nicanor, Andreas Metzner-Szigeth and Juan de Dios Gonzáles (eds.) 2011 e-Epistemología, Metaconocimiento y Virtualidad. México [in print]. 